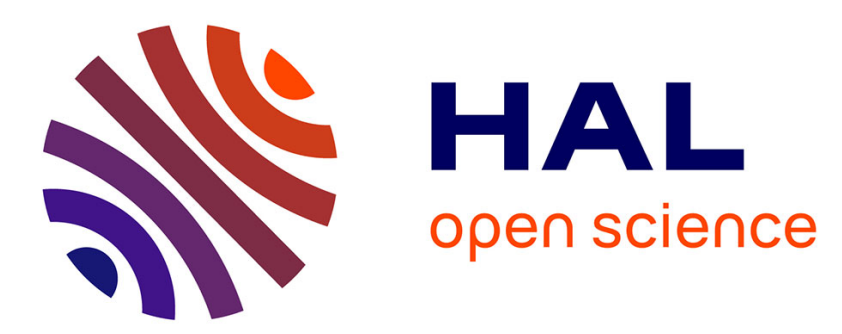

\title{
Structure, composition and function of interfaces in ceramic fibre/matrix composites \\ E. Pippel
}

\section{To cite this version:}

E. Pippel. Structure, composition and function of interfaces in ceramic fibre/matrix composites. Journal de Physique IV Proceedings, 1993, 03 (C7), pp.C7-1905-C7-1910. 10.1051/jp4:19937304 . jpa-00251948

\section{HAL Id: jpa-00251948 https://hal.science/jpa-00251948}

Submitted on 1 Jan 1993

HAL is a multi-disciplinary open access archive for the deposit and dissemination of scientific research documents, whether they are published or not. The documents may come from teaching and research institutions in France or abroad, or from public or private research centers.
L'archive ouverte pluridisciplinaire HAL, est destinée au dépôt et à la diffusion de documents scientifiques de niveau recherche, publiés ou non, émanant des établissements d'enseignement et de recherche français ou étrangers, des laboratoires publics ou privés. 


\title{
Structure, composition and function of interfaces in ceramic fibre/matrix composites
}

\author{
E. PIPPEL
}

Max-Planck-Institut für Mikrostrukturphysik, Weinberg 2, 06120 Halle (Saale), Germany

\begin{abstract}
Improving the properties of fibre reinforced ceramics and glasses by optimizing their microstructure requires the knowledge of this structure down to the atomic level. In these materials energy-dissipative processes during fracture particularly act within an interface layer or layer system between fibre and matrix which can either be produced by fibre coating, or which develops during the processing of the composites. Examples are presented of the microstructural phenomena of such layers revealed by HVEM and HREM and complemented by microchemical information via a nanoscale EDXS equipment. The investigations are carried out on Nicalon fibres in Duran glass as well as on Tyranno, Nicalon and carbon fibres in different SiC-matrices. Finally, a process is discussed which may control the important interface parameters.
\end{abstract}

\section{Introduction}

Advanced long fibre reinforced composite materials seem to be more promising than the monolithic ones in achieving a damage-bearing stress-strain behaviour, even in the high-temperature range.

In fibre-reinforced ceramics and glasses the following micromechanisms act as energy-dissipative processes: fibre debonding and pull-out, crack bridging and multiple crack formation $/ 1 /$. It is evident that these mechanisms are controlled by the special properties of the interface between fibre and matrix. In many cases, this interface is a complex layered transition region which can be formed during the processing of the composite as a result of thermo-chemical transport reactions, or which is due to a fibre coating during processing. These complex interfaces will be optimum with respect to debonding and pull-out processes implying the desired 
toughness and strength parameters if both their microstructure and microchemistry are known and if advanced mechanical testing methods will reveal corresponding structure/property relations.

The paper presents examples of characteristic interface phenomena revealed by TVEM, HREM and AEM, which were selected from studies of the systems Nicalon fibres in Duran glass, AVCO-fibres in Supremax glass, and Tyranno-, Nicalon- and carbon fibres in different SiC-matrices /2/. With respect to the microchemistry, both HREM and EDXS/EELS in the nanoprobe mode showed the interface region in most of these composites mainly consisting of (i) carbon layers of various degrees of graphitization and/or orientation, (ii) glassy regions, or (iii) a mixture of both with their composition strongly depending on the processing parameters. Finally, for special layered graphite structures, direct relations will be demonstrated between the structure and the mechanical function of interfaces .

\section{Microstructure of interfaces}

Fig. 1 presents the structure of a complex layer system formed by fibre coating and interface reactions between a carbon fibre (lower part) and an SiC-matrix (upper part) - grown by the pyrolysis of primary and infiltrated Si-polymer precursors. The porous region near the fibre surface is probably due to

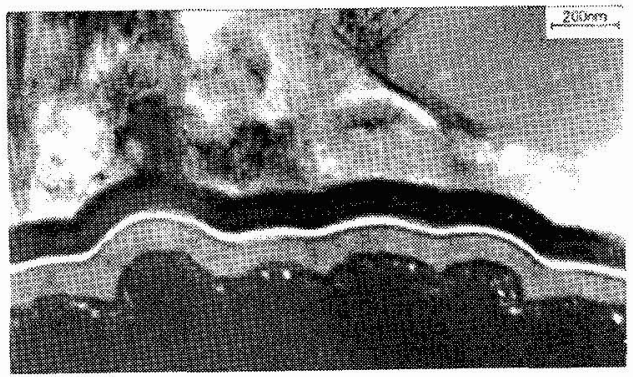

Fig. 1: Debonding between interface layers in C/SiC-composites

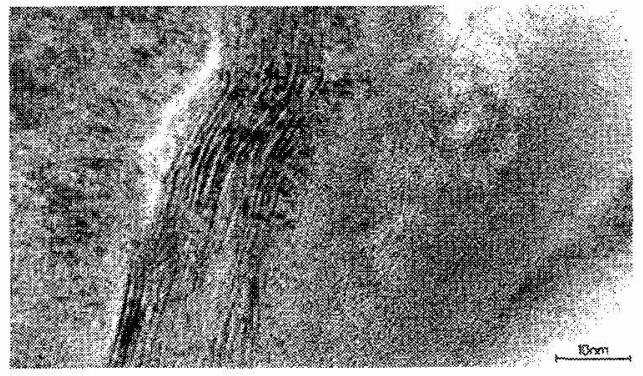

Fig.2: Interlayer structure in C-fibre reinforced SiC

thermal degradation during the coating process. The lower part of the interlayer system exactly follows the rough and bulgy surface structure being characteristic of the T-800 carbon fibre. On the other hand, near the matrix the interlayer has smoothed the rough surface of the fibre. Because of the geometry of the fibre surface affecting the pull-out length, this effect, which enhances with the interlayer thickness, may improve the materials toughness. Furthermore, Fig. 1 showes a debonding crack between two interface regions of different morphology, e.g. showing different degrees of graphitization as a function of the parameters of the coating process. 
Fig.2 presents a high-resolution image of a similar complex situation in the same system: On the left, the turbostratic graphite lamellae run more parallel on approaching the surface of the T-800 fibre. Interrupted by the beginning of a debonding crack a very regularly ordered graphite band has formed parallel to the interface as a first coating layer. Followed by a mesomorphic transition region and a second amorphous carbon layer there are the first SiC crystals of the matrix on the right. This kind of an interface structure may explain the debonding between individual interlayers as shown in Fig.1.

The formation of a very thin and simply structured interface is shown in Fig. 3: A suitable process route may reveal interface layers of only $10 \mathrm{~nm}$ in thickness in a Tyranno fibre/SiC-matrix composite. Graphite planes parallel to the fibre surface had formed.

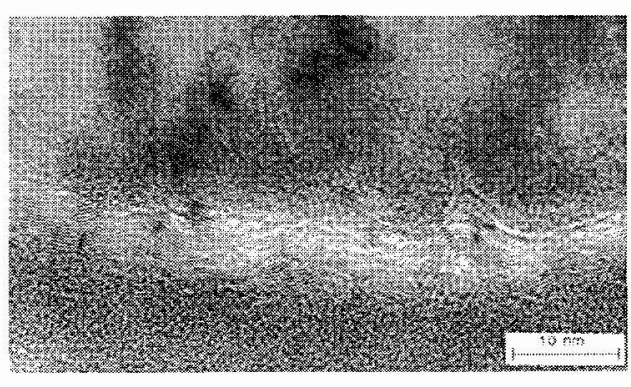

Fig.3: Thin graphite interlayer in $\mathrm{C} / \mathrm{SiC}$-ceramic

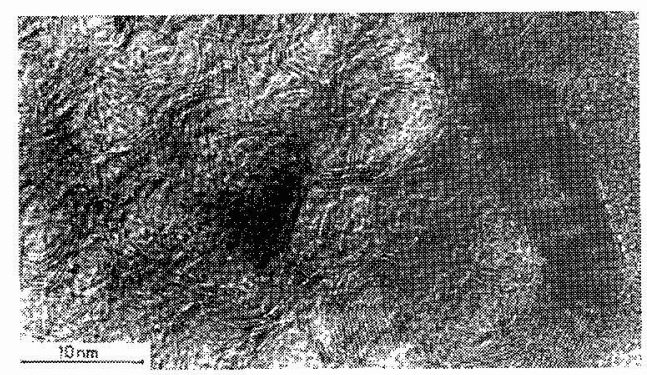

Fig.4: Graphite interlayers between Duran glass (right) and Nicalon fibre

\section{Chemistry of interfaces}

The formation of carbon and silicon rich interlayers by chemical reactions is being discussed for Nicalon in Duran glass: During hot pressing the Gibbs free energy decreases by the oxidation of the SiC-grains of the outer fibre regions, thermodynamically favouring the generation of silicon oxide and carbon by the oxidation reaction of $\mathrm{SiC}+\mathrm{O}_{2}=>\mathrm{SiO}_{2}+\mathrm{C} / 3 /$. This reaction is mainly controlled by the gradient of $\mathrm{SiO}_{2}$ activities between fibre and matrix. The $\mathrm{SiO}_{2}$ activity of the glass matrix is determined by its basicity, thus controlling the reaction kinetics.

In Fig. 4, the resulting interface layer of a specimen hot pressed for 4 hours at $12500 \mathrm{C}$ is shown to consist of two regions strongly differing in their microstructure: Neighbouring to the matrix (right) a parallel-oriented ribbon of graphite atomic planes has formed having a mean thickness of $8-10 \mathrm{~nm}$. Another layer of $80 \mathrm{~nm}$ in 
thickness of turbostratic graphite lamellae extends up to the fibre surface. Fig. 5 presents a corresponding EDXS line profile confirming that both layers are made up of carbon. Both the silicon and oxygen contents seem to be high inside the thin graphite layer. This suggests that the regularly arranged graphite interlayer may act as a barrier to the diffusion of the silicon oxide from the reaction region to the glass matrix as diffusion processes in the strongly anisotropic graphite lattice are favoured only along the weakly bonded hexagonal basic planes $/ 4 /$.
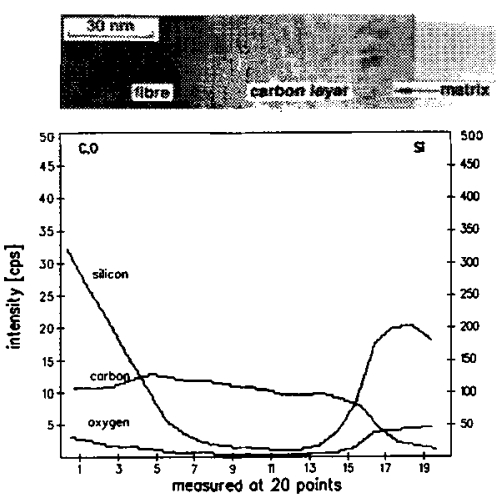

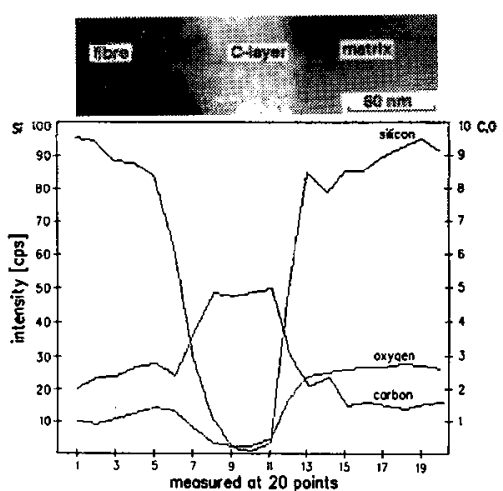

EDX line profiles across the interface of a Nicalon fibre reinforced Duran glass Fig.5: Hot pressed for $4 \mathrm{~h}$
Fig.6: Hot pressed for $5 \mathrm{~min}$

If the processing time is decreased to 5 minutes only the cellular part of the interlayer is formed. The corresponding EDXS profiles in Fig. 6 demonstrate that this layer consists of nearly pure carbon indicated by the box-like carbon signal and the complementary behaviour of silicon and oxygen. As the parallel-oriented graphite ribbon is missing here, along the cellular interlayer structure $\mathrm{SiO}_{2}$ may diffuse into the glass matrix.

The formation of cellular graphite interlayers by fibre degradation as described above also agrees with HREM observations: Corresponding to the composition and structure of Nicalon fibres the lattice plane image of a degraded fibre in Fig. 7 reveals $\mathrm{SiC}$-crystallites partly separated by graphite lamellae. The mean diameter of the crystallites is approximately the same as that of the graphite cells in the reaction layer (cf. Fig. 4). Consequently, fibre degradation can be regarded as a first step in the development of the interlayer structure by the oxidation of the SiC fibre. 


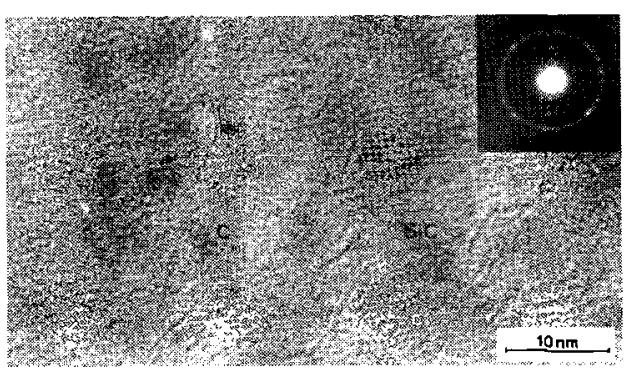

Fig.7: Microstructure of a degraded Nicalon fibre

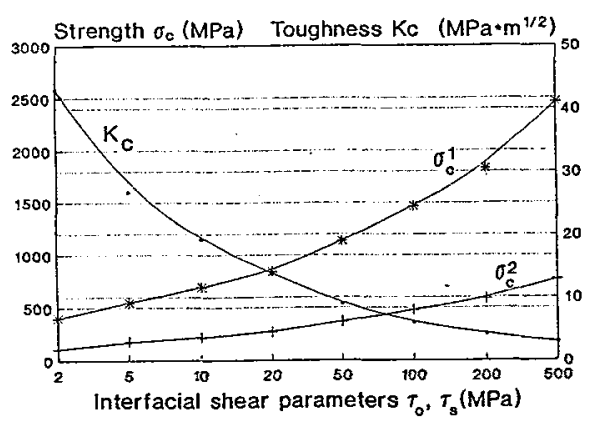

Fig.8: Strength and toughness of a Nicalon fibre reinforced Duran glass

\section{Function of interfaces}

Besides the thermomechanical and chemical accommodation of interfaces in advanced composite materials mentioned in chapter 2 , their most important functions are the protection against oxidation in the high-temperature range and to enable an appropriate mechanical gliding behaviour. Here, we will only deal with the latter one: If the bonding across the interface is too strong a matrix crack may cause a brittle failure of the material. Very weak interactions, however, prevent the load transfer from the fibre to the matrix, with only a small part of energy being dissipated during the pull-out process. Another problem associated is the difficulty of simultaneously optimizing the strength $\sigma_{\mathrm{C}}$ and the toughness $\mathrm{K}_{\mathrm{C}}$. Following the relations given in $/ 5 /$ these quantities contrarily depend on the important interface parameters $\tau_{\mathrm{O}}$ (debonding strength) and $\tau_{\mathrm{S}}$ (frictional shear strength). For the system Nicalon fibre/Duran glass this behaviour is illustrated in Fig. 8 with the two $\sigma_{c}$-curves representing different fracture surface energies of the matrix. A compromise between strength and toughness seems to be possible for mean values of the interface parameters, provided there is a suitable microstructural interface mechanism, which controls the parameters $\tau_{0}$ and $\tau_{\mathrm{s}}$.

Similar to Nicalon fibre reinforced Duran glass (cf. Fig. 4) there were parallel-oriented graphite bands on the fibre side of the interface region in the system Tyranno fibre/SiC-matrix (Fig. 9). We assume that the extension of this regular graphite layer can be used as an essential interface parameter governing the shear moduli $\tau_{0}$ and $\tau_{\mathbf{S}}$ mentioned above. Because of the very small binding force between 
the basic planes in graphite (van der Waals type) the wrapping up of the fibres with these

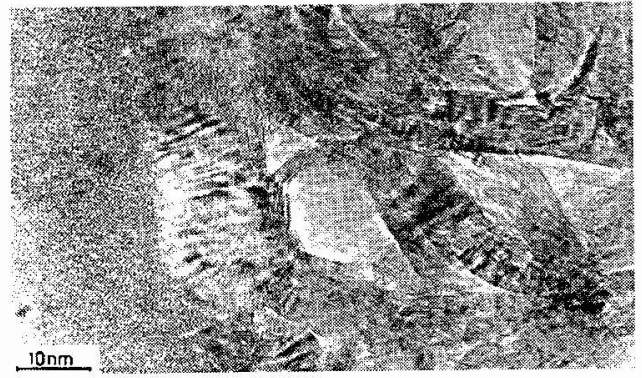

Fig.9: Parallel-aligned graphite lamellae near a carbon fibre (left)

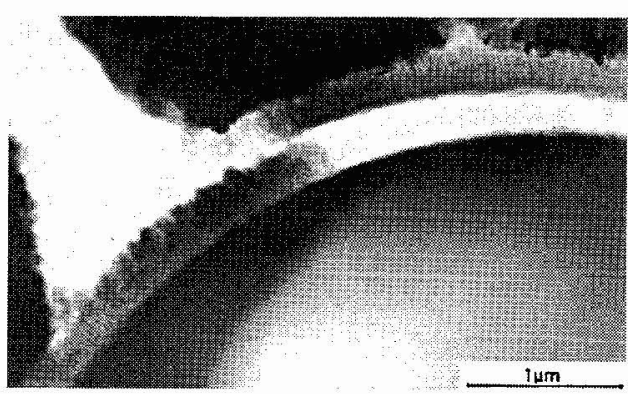

Fig.10: Crack propagation between a Tyranno fibre and the SiC-matrix

planes can effect a quasi-laminar pull-out thus acting as a solid lubricant. Moreover, the interface coefficients can be changed by a controlled generation of the graphite bands. This should be possible as the microstructure of pyrolytic carbon can be varied over a wide range by controlling the parameters of the deposition process $/ 6 /$. The action of the described effect of the graphite bands is demonstrated in Fig.10: If the macrocrack meets the fibre/matrix interface the fibre surface seperates from the carbon layer. This is the very location of the graphite structure parallel- aligned and weakly bonded shown, in Fig. 9 .

\section{Acknowledgements}

The authors are grateful to Dr. G.Grathwohl, Universität Karlsruhe, Dr. W.Pannhorst, Schott Glaswerke Mainz, Dr. R.Ostertag, Dornier GmbH Friedrichshafen, and Dr. A.Mühlratzer, MAN Technologie AG München, for providing the materials. We also thank our co-worker R.Schneider for performing the EDXS analysis.

\section{References}

/1/ A.G.Evans, D.B.Marshall: Acta matall. 37 (1989) 2567

I2/ G.Grathwohl, A.Hähnel, B.Meier, E.Pippel, J.Woltersdorf: J. Eur. Ceram. Soc. 10 (1992) 1

/3/ R.F.Cooper, K.Chyung: J. Mat. Sci. 22 (1987) 3148

14/ B.T.Kelly: Physics of Graphite, Appl. Sci. Publ. London, New Jersy 1981

15/ R.H.Jones et al.:Mat. Sci. Forum 46 (1989) 277

16/ J.C.Bokros: Chemistry and Physics of Carbon, Vol.5, P.L.Walker(Ed.), Dekker, New York 1969 